\title{
SISTEM PENDETEKSI DAN PERINGATAN DINI UPWELLING
}

\author{
Andi Ircham Hidayat ${ }^{1}$
}

${ }^{1}$ STIE Nobel Indonesia, Makassar, Indonesia

${ }^{1}$ hidayat.ircham@gmail.com

\begin{abstract}
ABSTRAK
Penelitian ini bertujuan membangun sebuah sistem pendeteksi dan peringatan dini upwelling yang dapat memberikan informasi akan terjadianya fenomena upwelling. Sistem yang dibuat memiliki komponen utama yaitu sebuah alat raspberry pi sebagai sistem kontrol dan 2 komponen sensor yang digunakan untuk mengukur parameter suhu pada lapisan air. Sistem ini mampu memberikan informasi melalui aplikasi berbasis android dan website apabila terdapat tanda akan terjadinya fenomena upwelling. Proses pengiriman data menggunakan protokol HTTP dengan fungsi POST. Hasil penelitian dengan melakukan pengujian sebanyak 10 kali untuk masing-masing sensor menunjukkan bahwa persentase tingkat akurasi kedua sensor bernilai antara 98,00\% sampai dengan 99,00\%. Sistem ini diaplikasikan pada keramba jaring apung di danau untuk mendapatkan informasi yang efektif dan efisien agar dapat meminimalisir kerugian yang diakibatkan oleh fenomena upwelling.
\end{abstract}

Kata Kunci- Peringatan Dini, Raspberry, Upwelling, Protokol HTTP

\begin{abstract}
This research aims to build an upwelling detection and early warning system that can provide information on the occurrence of upwelling phenomena. The system has the main component of a raspberry pi tool as a control system and 2 sensor components used to measure temperature parameters in the water layer. This system is able to provide information through android-based applications and websites there are signs of the occurrence of upwelling phenomenon. The process of sending data using http protocol with POST function. The results of 10 tests for each sensor showed that the proportion of accuracy of both sensors was between $98.00 \%$ and $99.00 \%$. This system is applied to floating net cages in the lake to obtain effective and efficient information in order to minimize losses caused by the upwelling phenomenon.
\end{abstract}

Keywords—Early Warning, Raspberry, Upwelling, HTTP Protocol 
Jurnal Ilmiah Ilmu Komputer Vol. 7, No. 1, April 2021

Fakultas Ilmu Komputer

Universitas AL Asyariah Mandar

\section{PENDAHULUAN}

Dalam budi daya perairan atau budi daya perikanan (ikan dan non ikan) terdapat faktor eksternal yang tidak bisa dikontrol atau dikendalikan oleh petani ikan, kecuali dihindari yaitu terjadinya mati massal akibat dari fenomema alam seperti upwelling, upwelling adalah fenomena alam dimana terjadi penaikan lapisan hipolimnion ke permukaan, lapisan hipolimnion ini bersifat toksik, kandungan oksigen rendah / defisit oksigen, mengandung gas beracun (amonia, hidrogen sulfida, metana, dan fosfin). [1].

Upwelling dapat mengakibatkan kematian masal pada ikan peliharaan Petani ikan Karamba di danau-danau air tawar. Sehingga sangat merugikan petani ikan.

Parameter suhu air dapat dijadikan parameter untuk mengetahui secara dini akan adanya fenomena upwelling. Air yang bersuhu lebih dingin mempunyai berat jenis yang lebih besar dibandingkan air yang suhunya lebih panas. Ketika berat jenis air di permukaan lebih besar dari air pada lapisan air lebih dalam, air permukaan akan turun mendesak air bagian dalam, dan terjadilah arus balik vertical. Sebenarnya, yang paling merugikan pada proses upwelling di danau atau waduk ini adalah naiknya tumpukan material organik serta gas beracun. Hal ini terjadi karena perairan dasar waduk dan danau cenderung statis sehingga biasanya kekurangan oksigen. Kurangnya oksigen mengakibatkan tidak sempurnanya proses penguraian material organik yang menumpuk di dasar. Efek penguraian yang tidak sempurna itu akan menghasilkan gas-gas beracun $\mathrm{H} 2 \mathrm{~S}$, metan (CH4), maupun amoniak (NH3).

Dari tingginya kerugian yang ditimbulkan maka suatu sistem yang dapat mendeteksi dan memberi peringatan secara dini kepada petani ikan atau pemilik keramba akan adanya fenomena upwelling sangat dibutuhkan, guna meminimalisir kerugian akibat adanya aktifitas bawah air yang bisa datang kapan saja.

\section{TINJAUAN PUSTAKA}

\subsection{Waduk}

Waduk adalah daerah yang digenangi badan air sepanjang tahun serta dibentuk atau dibangun atas rekayasa manusia. Waduk dibangun untuk beberapa kebutuhan diantaranya: (1) untuk irigasi; (2) penyedia energi listrik melalui pembangkit listrik tenaga air (PLTA); (3) penyedia air minum; (4) pengendali banjir; (5) rekreasi; (6) perikanan; dan (7) transportasi. Waduk dibangun dengan cara membendung aliran sungai sehingga air sungai tertahan sementara dan menggenangi bagian daerah aliran sungai (DAS) atau watershed yang rendah. Waduk dapat dibangun didataran rendah maupun dataran tinggi. Waduk yang dibangun di dataran tinggi umumnya bedasar dan bertebing curam sehingga metode hampang sulit diterapkan. Di perairan dalam dan dapat diterapkan metode sangkar dan Keramba Jaring Apung. [4].

\subsection{Keramba Jaring Apung (KJA)}

Keramba jaring apung adalah salah satu wadah budidaya perairan yang cukup ideal, yang ditempatkan di badan air dalam, seperti waduk, danau, dan laut. Keramba jaring apung merupakan salah satu wadah untuk penerapan budidaya perairan sistem intensif. Prinsipnya semua jenis ikan laut dan ikan tawar dapat dipelihara pada keramba jaring apung.

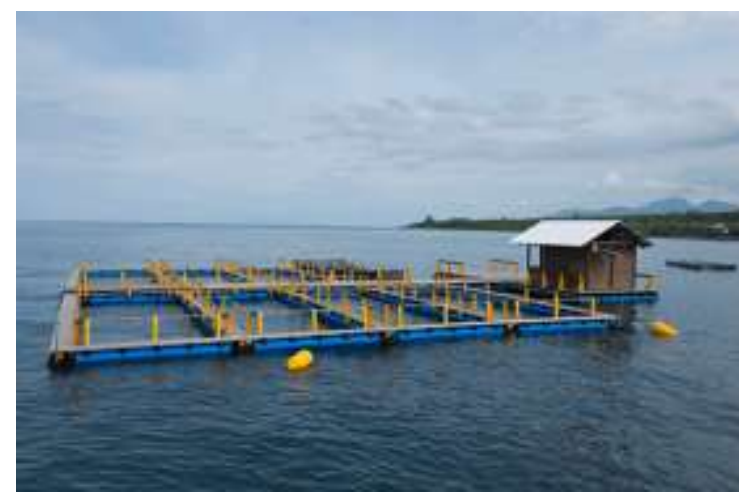

Gambar 1. Keramba Jaring Apung

\subsection{Sistem Peringatan Dini}

Sistem peringatan dini adalah sistem (rangkaian proses) pengumpulan dan analisis data serta desiminasi informasi tentang keadaan darurat atau kedaruratan. [5]

Informasi yang berhubungan dengan bahaya yang akan terjadi biasanya berupa tanda / sinyal tertentu yang disebut alarm (alert). Alarm bertujuan agar pihak-pihak yang terkait dengan bahaya tersebut mampu mempersiapkan diri untuk mengatasi, atau terhindar dari bencana.

\subsection{Monitoring}

Sistem monitoring merupakan suatu proses untuk mengumpulkan data dari berbagai sumber daya. Biasanya data yang dikumpulkan merupakan data yang realtime. [6].

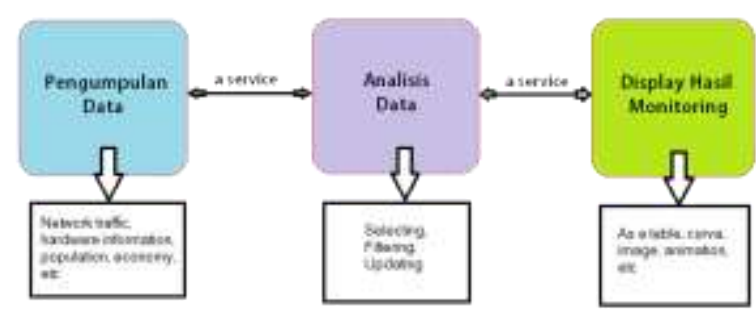

Gambar 2. Tahapan Sistem Monitoring

\subsection{Suhu Air}

Suhu mempengaruhi aktivitas metabolisme organisme, karena itu penyebaran organisme baik di lautan maupun di perairan ari tawar dibatasi oleh suhu perairan tersebut. Suhu hangat berpengaruh terhadap kehidupan dan pertumbuhan biota air. Secara umum laju pertumbuhan meningkat sejalan dengan kenaikan suhu, dapat menekan kehidupan hewan budidaya bahkan menyebabkan kematian bila penigkatan ekstrim (drastis). [4] 
Jurnal Ilmiah Ilmu Komputer Vol. 7, No. 1, April 2021

Fakultas Ilmu Komputer

Universitas AL Asyariah Mandar

Suhu air dapat mempengaruhi kehidupan biota air secara tidak lansung, yaitu melalui pengaruhnya terhadap kelarutan oksigen dalam air. Semakin tinggi suhu air, semakin rendah daya larut oksigen dalam air, dan sebaliknya.

\section{METODE PENELITIAN}

Perancangan sistem dilakukan sebagai langkah awal sebelum terbentuknya suatu sistem beserta rangkaian elektronik pendukungnya yang siap direalisasikan. Hal ini dilakukan agar yang dibuat dapat berjalan sebagaimana mestinya.

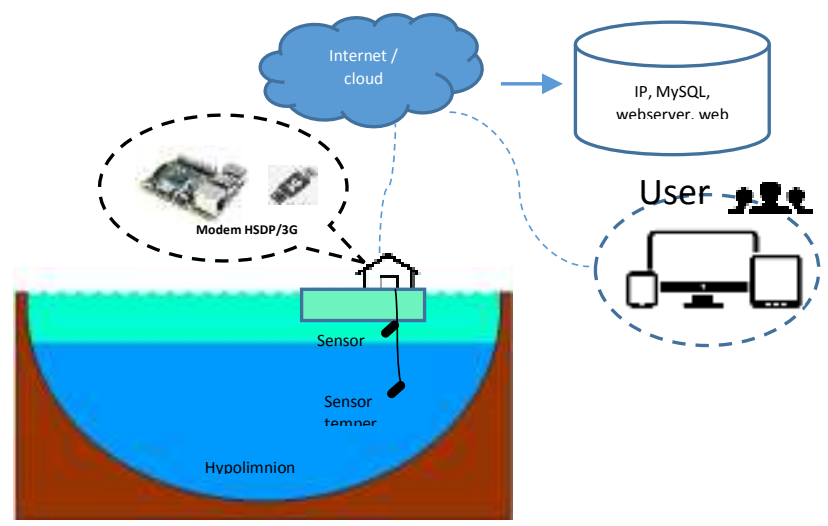

Gambar 3. Rancangan Sistem

Metode perancangan yang dilakukan merupakan deskripsi yang disederhanakan dari proses tahapan penelitian, yaitu proses pembuatan perangkat lunak yang sekuensial dimulai dari tahap analisis sistem sampai pengujian / evaluasi

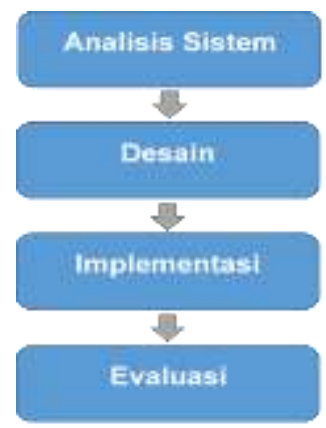

Gambar 4. Rancangan Penelitian

\subsection{Analisis Sistem}

Pada tahapan ini berlangsung dengan malakukan studi awal mengenai masalah yang ada, agar dapat diantisipasi segala permasalahan yang terkait dengan akan diterapkan sistem baru. Adapun masalah yang terindetifakasi (1) Bagaimana merancang sistem peringatan secara online yang dapat mendeteksi kemungkinan terjadinya Upwelling, (2) Bagaimana menggunakan atau memanfaatkan sensor suhu untuk mengawasi aktivitas bawah air agar dapat terpantau secara realtime.

\subsection{Desain}

Pada tahapan ini dikembangkan berdasarkan hasil analisis kebutuhan sistem yang diperoleh pada tahap sebelumnya. Spesifikasi kebutuhan sistem diterjemahkan ke dalam fungsi-fungsi dengan interface yang dibutuhkan.

Setelah proses perancangan telah dibuat maka dilanjutkan dengan mendesain proses, tampilan program baik inputan data dan output data untuk memudahkan pengguna sistem. Pada tahap ini teknik pengkodean dimodelkan kemudian diproses dalam tahap coding. Proses desain ini merupakan proses penerjemahan dari analisis kebutuhan kedalam bentuk representase sebuah model perangkat lunak yang dapat dinilai kualitasnya sebelum dilakukan coding.

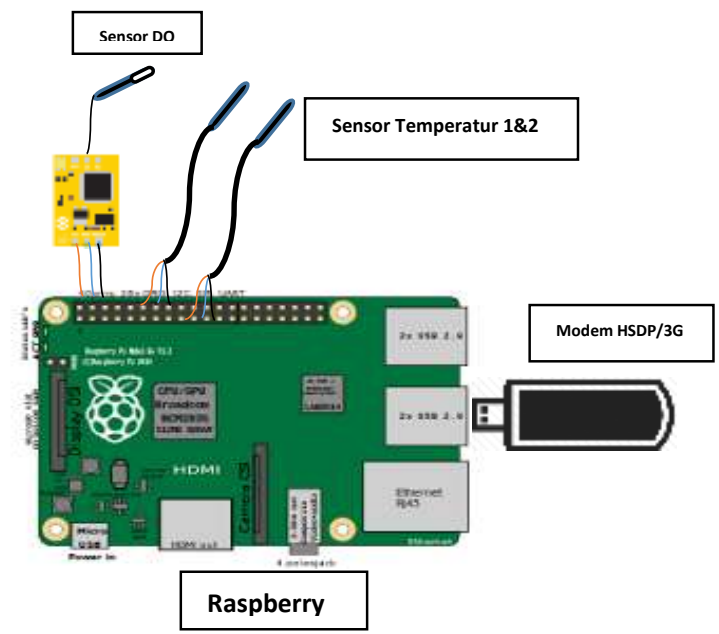

Gambar 5. Blog Diagram Perangkat Keras Sistem

Gambar 5 merupakan desain Sistem perangkat keras secara keseluruhan, menggunakan Raspberry sebagai sistem kontrol.

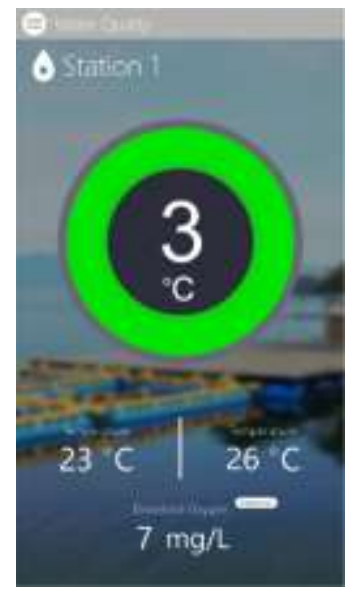

Gambar 6. Desain antarmuka aplikasi mobile

Pada perancangan awal desain antar muka aplikasi terdapat 2 rancangan sistem yang akan menampilkan informasi pengukuran yang akan dilakukan. Informasi pengukuran sensor temperatur dan sensor oksigen terlarut akan menjadi tampilan awal pada saat aplikasi di akses. 
Jurnal Ilmiah Ilmu Komputer Vol. 7, No. 1, April 2021

Fakultas Ilmu Komputer

Universitas AL Asyariah Mandar

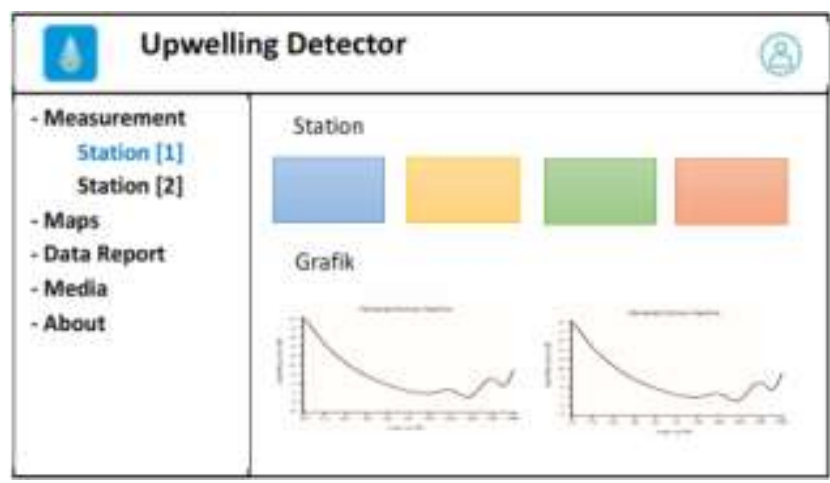

Gambar 7. Rancangan antarmuka website

Gambar 7 merupakan rancangan tampilan pada website untuk melihat data yang dikirim oleh sensor melalui sensor node (raspberry), tampilan dashboard akan menjadi tampilan awal ketika website ini diakses.

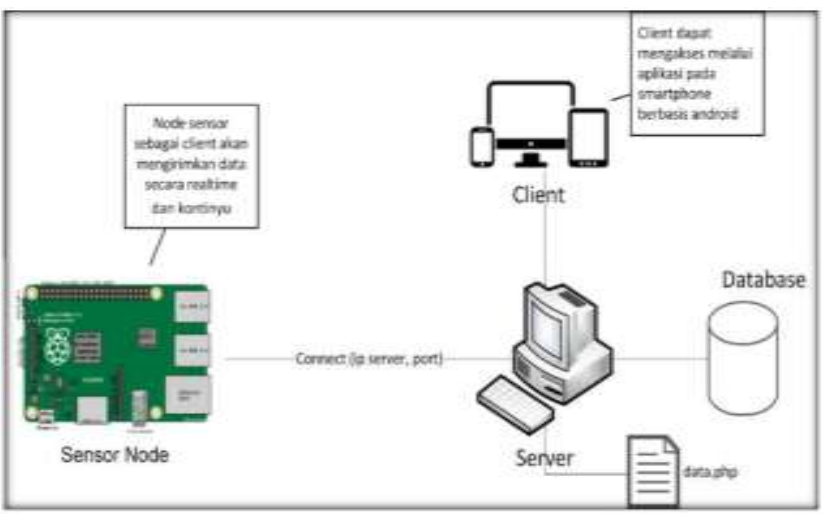

Gambar 8. Metode Pengiriman Data ke Database Server

Gambar 8 merupakan gambaran proses pengirman data ke server, digunakan protokol HTTP dengan fungsi POST. Pengiriman data didahului dengan melakukan koneksi ke server. Jika server tersedia, maka proses selanjutnya adalah melakukan pengiriman data dengan fungsi POST.

Perancangan sistem pada sisi server yang berfungsi sebagai penerima data yang dikirim oleh sensor melalui Raspberry. Data yang diterima akan disimpan ke dalam database dengan menggunakan php sebagai pendukung ke database, tabel dan query sql agar data yang diterima oleh php dapat dimasukkan ke dalam database. Pengguna dapat menerima peringatan dan melihat nilai - nilai sensor dengan menggunakan aplikasi pada smartphone berbasis android

\subsection{Implementasi Sistem}

Pada tahap ini dilakukan pengujian dari sistem berupa ujicoba secara lansung pada lokasi penelitian baik danau/waduk. Serta pengujian pada prototype yang menyerupai danau/waduk.
Hasil yang diperoleh dari pengujian sistem dievaluasi untuk meningkatkan tingkat keakurasian dalam sistem pendeteksi dan peringatan dini upwelling.

\section{HASIL PENELITIAN}

Sistem pendeteksi dini upwelling ini bersifat multiuser atau dapat diakses oleh lebih dari satu user, dimana saja dan kapan saja dengan menggunakan laptop atau smartphone berbasis android yang terkoneksi dengan internet. Sistem ini dapat diakses melalui alamat website project.irchamhidayat.com atau dapat mengunduh aplikasi upwelling detector pada google playstore

\subsection{Pengujian Sistem}

Pada tahapan pengujian sistem yaitu pengujian fungsional untuk menguji kinerja sistem secara keseluruhan. Pengujian ini berfokus pada fungsi-fungsi setiap menu yang telah dirancang dalam sistem yang telah dibangun

\subsubsection{Hasil Pengembangan Perangkat Keras}

Berikut bentuk alat sistem pendeteksi dini upwelling yang terdapat pada keramba jaring apung

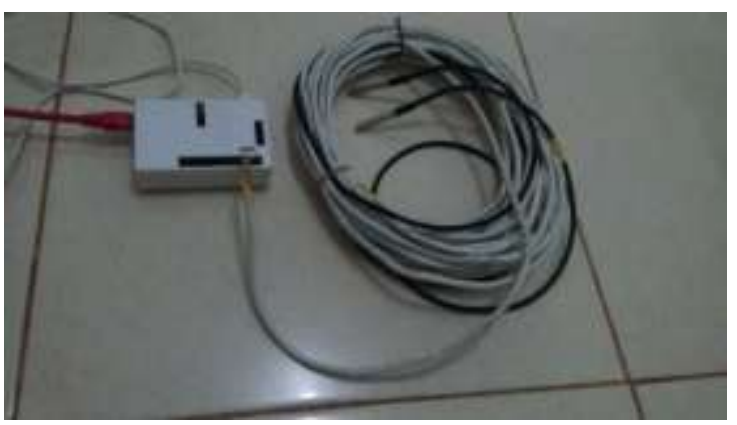

Gambar 9. Hasil Rancangan Perangkat Keras

Terdapat 2 buah sensor suhu yang akan mengukur suhu air pada kedalaman 7 dan 15 meter, data yang diterima sensor akan dikirimkan ke sistem kontrol berupa perangkat Raspberry. Sistem akan membandingkan data suhu dari masing-masing sensor, apabila suhu pada lapisan bawah sama atau lebih rendah dari suhu pada lapisan atas waduk maka sistem akan memberikan peringatan berupa alarm buzzer.

\subsubsection{Rancangan Kondisi Alarm}

Untuk memberi peringatan akan terjadinya fenomena upwelling akan ditempatkan outdoor alarm siren/buzzer pada lokasi keramba jaring apung dan alarm ringtone pada aplikasi, akan berbunyi pada kondisi sebagai berikut :

\subsection{Evaluasi Sistem}

Tabel 1. Kondisi Suhu dan Alarm 
Jurnal Ilmiah Ilmu Komputer Vol. 7, No. 1, April 2021

Fakultas Ilmu Komputer

Universitas AL Asyariah Mandar

\begin{tabular}{|c|c|c|c|c|c|}
\hline \multirow[b]{2}{*}{ No. } & \multicolumn{2}{|c|}{ Kondisi } & \multirow[b]{2}{*}{$\begin{array}{c}\text { Selisih } \\
\text { Suhu }\end{array}$} & \multirow[b]{2}{*}{$\begin{array}{c}\text { On-Site } \\
\text { Alarm }\end{array}$} & \multirow[b]{2}{*}{$\begin{array}{c}\text { App } \\
\text { Alarm }\end{array}$} \\
\hline & $\begin{array}{l}\text { Suhu } \\
\text { Bawah }\end{array}$ & $\begin{array}{c}\text { Suhu } \\
\text { Atas }\end{array}$ & & & \\
\hline 1 & $28.00^{\circ} \mathrm{C}$ & $31.00^{\circ} \mathrm{C}$ & $3{ }^{\circ} \mathrm{C}$ & Normal & Normal \\
\hline 2 & $28.00^{\circ} \mathrm{C}$ & $28.00^{\circ} \mathrm{C}$ & $0{ }^{\circ} \mathrm{C}$ & Aktif & Aktif \\
\hline 3 & $28.00^{\circ} \mathrm{C}$ & $27.00^{\circ} \mathrm{C}$ & $-1{ }^{\circ} \mathrm{C}$ & Aktif & Aktif \\
\hline
\end{tabular}

Pada umumnya di wilayah tropis memiliki perbedaan suhu air permukaan dengan bagian dasar hanya sekitar 2 - 3 derajat celcius. [12].

\subsubsection{Hasil Rancangan dan Pengujian Aplikasi}

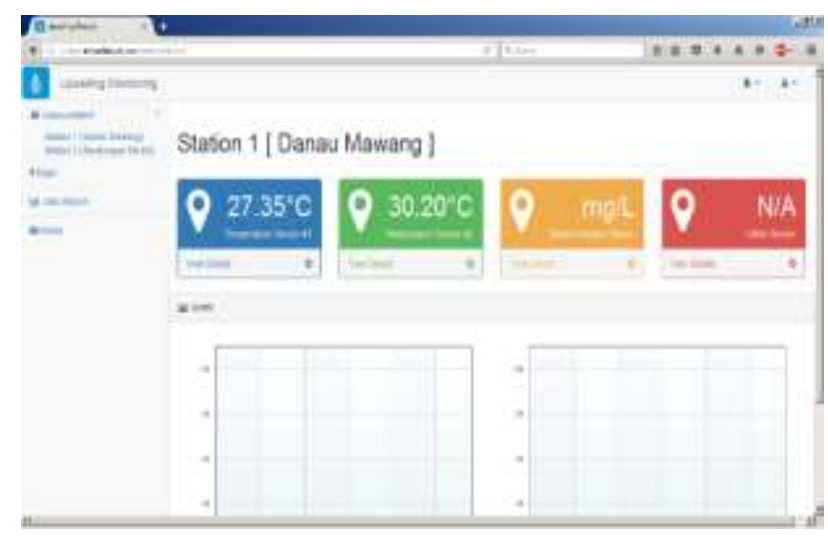

Gambar 10. Tampilan measurement pada website

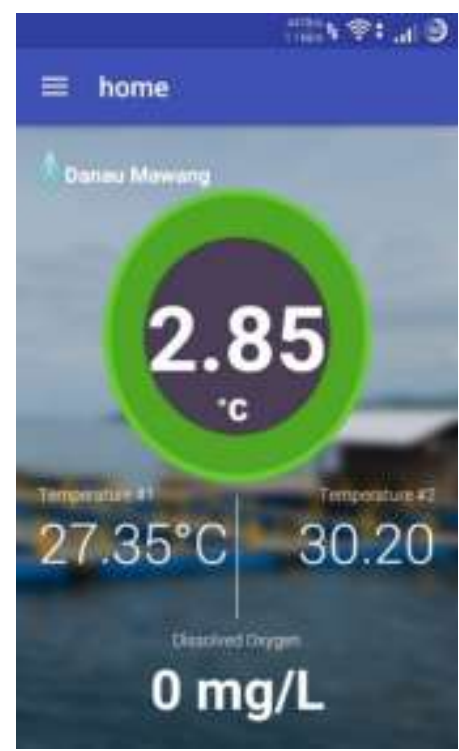

Gambar 11. Tampilan pengukuran pada aplikasi

Pada gambar 10 dan 11 menunjukkan nilai dari hasil pengukuran yang dilakukan di lokasi danau Mawang. Halaman measurement pada website untuk menapilkan nilai dari masing - masing sensor dan halaman measurement pada aplikasi mobile menampilkan nilai dan selisih dari sensor, terlihat selisih hasil pengukuran sebesar 2.85 derajar celcius.

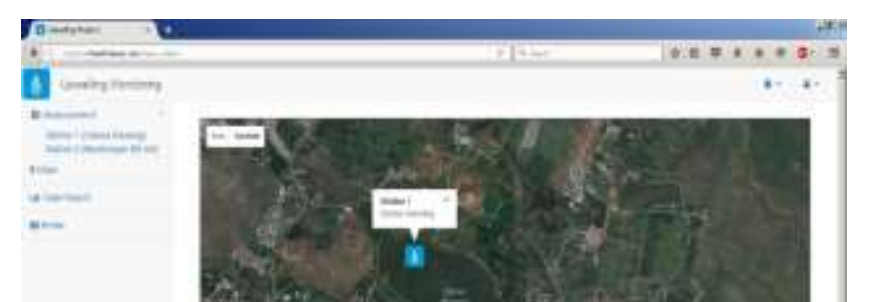

(P) ISSN 2442-451X

(O) ISSN 2503-3832
Gambar 12. Tampilan Maps Station pada Website

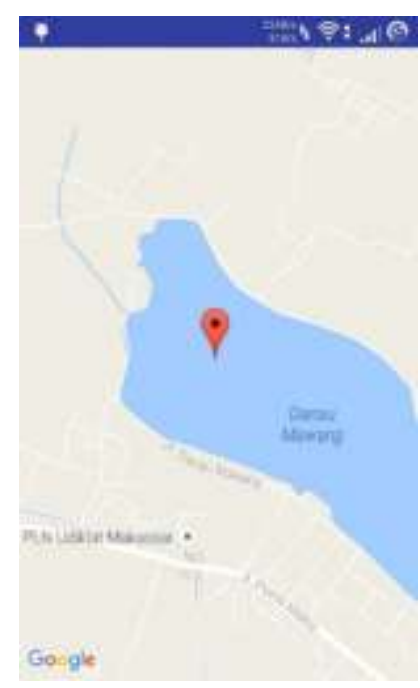

Gambar 13. Tampilan Maps Station pada Aplikasi

Menu maps station pada halaman website dan Aplikasi Mobile untuk menampilkan lokasi dari masing - masing sensor node.

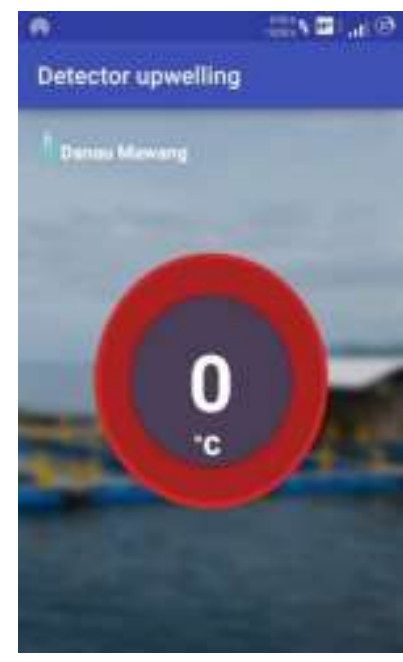

Gambar 14. Notifikasi Simulasi Alarm pada Aplikasi

Gambar 14 menunjukkan munculnya alarm pada aplikasi dikarenakan sensor mendeteksi suhu yang sama pada masing-masing lapisan air.

4.2 Pengujian Sensor 
Jurnal Ilmiah Ilmu Komputer Vol. 7, No. 1, April 2021

Fakultas Ilmu Komputer

Universitas AL Asyariah Mandar

Pengujian ini dilakukan bertujuan untuk menilai keakuratan dari sensor suhu yang digunakan pada sistem ini, pengujian dilakukan dengan membandingkan nilai dari setiap sensor dengan termometer digital. Untuk mengambarkan keberhasilan sensor "Tingkat Keberhasilan Sistem". Dimana tingkat akurasi keberhasilan sensor ini dihitung dengan perhitungan kesalahan absolut relatif fraksional. Pengujian pada sensor pertama yang akan ditempatkan pada kedalaman 15 meter. Menggunakan uji sebanyak 10 kali, dengan rumus:

Akurasi pengujian $1+$ Akurasi pengujian $2+$ Akurasi pengujian $3+$ Akurasi pengujian $4+$ Akurasi pengujian $5+$ Akurasi pengujian $6+$ Akurasi pengujian $7+$ Akurasi pengujian $8+$ Akurasi pengujian $9+$ Akurasi pengujian 10

10

Tabel 2. Pengujian Sensor 1

\begin{tabular}{ccccc}
\hline No. & Sensor & Thermometer & Selisih & Akurasi \\
1 & $28,70{ }^{\circ} \mathrm{C}$ & $28.30^{\circ} \mathrm{C}$ & 0,40 & 99,60 \\
2 & $27,60^{\circ} \mathrm{C}$ & $27.20^{\circ} \mathrm{C}$ & 0,40 & 99,60 \\
3 & $50,80^{\circ} \mathrm{C}$ & $50.70{ }^{\circ} \mathrm{C}$ & 0,10 & 99,90 \\
4 & $50.70{ }^{\circ} \mathrm{C}$ & $50.50{ }^{\circ} \mathrm{C}$ & 0,20 & 99,80 \\
5 & $35.30^{\circ} \mathrm{C}$ & $34.70{ }^{\circ} \mathrm{C}$ & 0,60 & 99,40 \\
6 & $34.90^{\circ} \mathrm{C}$ & $34.30^{\circ} \mathrm{C}$ & 0,60 & 99,40 \\
7 & $34.70^{\circ} \mathrm{C}$ & $34{ }^{\circ} \mathrm{C}$ & 0,70 & 99,30 \\
8 & $34.30^{\circ} \mathrm{C}$ & $33.90^{\circ} \mathrm{C}$ & 0,40 & 99,60 \\
9 & $43^{\circ} \mathrm{C}$ & $42.30^{\circ} \mathrm{C}$ & 0,70 & 99,30 \\
10 & $42.9^{\circ} \mathrm{C}$ & $42.10^{\circ} \mathrm{C}$ & 0,80 & 99,20 \\
\hline
\end{tabular}

Berdasarkan tabel diatas tingkat keakurasian pengujian data 1 sampai 10, maka rata rata akurasinya adalah 99,51\%

Tabel 3. Pengujian Sensor 2

\begin{tabular}{ccccc}
\hline No. & Sensor & Thermometer & Selisih & Akurasi \\
1 & $31,10^{\circ} \mathrm{C}$ & $\begin{array}{c}\text { Digital } \\
1.10^{\circ} \mathrm{C}\end{array}$ & 0,00 & 100 \\
2 & $27.30^{\circ} \mathrm{C}$ & $27.20^{\circ} \mathrm{C}$ & 0,10 & 99,90 \\
3 & $50.70^{\circ} \mathrm{C}$ & $50.70^{\circ} \mathrm{C}$ & 0,00 & 100 \\
4 & $50.500^{\circ} \mathrm{C}$ & $50.50^{\circ} \mathrm{C}$ & 0,00 & 100 \\
5 & $35.30^{\circ} \mathrm{C}$ & $34.70^{\circ} \mathrm{C}$ & 0,60 & 99,40 \\
6 & $34.90^{\circ} \mathrm{C}$ & $34.30^{\circ} \mathrm{C}$ & 0,60 & 99,40 \\
7 & $34.60^{\circ} \mathrm{C}$ & $34^{\circ} \mathrm{C}$ & 0,60 & 99,40 \\
8 & $33.90^{\circ} \mathrm{C}$ & $33.90^{\circ} \mathrm{C}$ & 0,00 & 100 \\
9 & $42.30^{\circ} \mathrm{C}$ & $42.30^{\circ} \mathrm{C}$ & 0,00 & 100 \\
10 & $42.70^{\circ} \mathrm{C}$ & $42.10^{\circ} \mathrm{C}$ & 0,60 & 99,40 \\
\hline
\end{tabular}

Berdasarkan tabel diatas tingkat keakurasian pengujian data 1 sampai 10, maka rata rata akurasinya adalah 99,75\%. Pengujian ini sensor kedua ditempatkan pada kedalaman 7 meter.
(P) ISSN 2442-451X

(O) ISSN 2503-3832

\section{KESIMPULAN}

Berdasarkan hasil penelitian yang telah dilakukan mulai dari awal hingga proses pengembangan, implementasi, dan evaluasi, maka dapat disimpulkan bahwa secara kesulurahan sistem berfungsi dengan baik, nilai dari sensor dapat dikirim ke database server melalui jaringan internet. Selanjutnya nilai sensor dapat dimonitoring melalui website dan aplikasi pada smartphone.

Sistem ini juga dapat memberikan peringatan atau warning berupa alarm pada lokasi sensor node dan pada website aplikasi pada smartphone berbasis android apabila suhu pada lapisan epilimnion lebih rendah daripada suhu pada lapisan hypolimnion.

\section{Daftar Pustaka}

[1] Budi, M., Henry, B. Utari., Supriyadi. 2013. Upwelling di Jatiluhur dan Cirata: Fenomena Unik Arus Balik. Dalam Majalah BAIT CP Prima, Vol 5.

[2] Kementrian Kelautan dan Perikanan Republik Indonesia, (2014) dan (2016) website [online]. Available:

http://www.bkipm.kkp.go.id/new_puskari/detil_kegia tan.php?id=1869

[3] Jangkaru, Z. 1995. Pembesaran Ikan Air Tawar di Berbagai Lingkungan Pemeliharaan. Penerbit PT. Penebar Swadaya, Jakarta.

[4] M. Ghufran H Kordi K., Andi Baso Tancung. 2010. Pengelolaan Kualitas Air Dalam Budidaya Perairan. Penerbit PT. Rineka Cipta, Jakarta.

[5] Daryono, 2005, Prediksi dan Gejala Awal Tsunami, Balai Meteorologi dan Geofisika Wilayah, Bali.

[6] Dasril. 2015. Sistem SCADA Untuk Pengelolaan Tambak. Program Pascasarjana STMIK Handayani Makassar.

[7] Ahmad, T., E. Ratnawati dan M.J.R. Yakob, 1998. Budi Daya Bandeng Secara Intensif. Penerbit PT. Penebar Swadaya, Jakarta.

[8] Zonneveld, N., E.A. Huisman dan J.H. Boon, 1991. Prinsip-Prinsip Budidaya Ikan. Penerbit PT. Gramedia Pustaka Utama, Jakarta.

[9] Cholik, F., 1988. Pengaruh Mutu Air Terhadap Produksi Udang Tambak. Makalah Seminar sehari Pentingnya Pengelolaan Mutu Air dalam Meningkatkan Produktivitas Tambak Udang, Semarang, 20 Juli 1998.

[10] Rintania Elliyanti Nuryaningsih. 2013. Sistem Deteksi Upwelling Citra SST Modis Menggunakan Fuzzy KMeanz Clustering. Pascasarjana, Fakultas Teknik, Universitas Gajah Mada Yogyakarta.

[11] Arief Nur Rahman, Octa Heriana, Taufiqqurrahman. 2014. Perancangan Sistem Aplikasi Pemantau Kualitas Air Berbasis Web. Jurnal Sistem Komputer Vol.4, No 2 November 2014, 2087-4685 
Universitas AL Asyariah Mandar

[12] Effendi, F. 2003. Telaah Kualitas Air (Pengelolaan Sumberdaya dan Lingkungan Perairan). Jakarta, Kanisius (Anggota IKAPI). 